\title{
From dispassionate law to compassionate outcomes in health-care law, or not
}

\author{
Hazel Biggs"
}

\begin{abstract}
Health-care law presents numerous challenges to the conception of the law as a dispassionate arbiter of disputes or protector of rights. Issues relating to end-of-life care, the assessment of mental capacity and decision-making for those who lack capacity, amongst others, epitomise the complex nature of healthcare law. They also raise globally applicable questions about discrimination, or equal protection, as well as concerns for relief of suffering, the assessment of best interests and the exercise of individual autonomy. This paper will evaluate the extent to which law's traditional objectivity (dispassion) is undermined by the introduction of concerns about compassion into judicial and executive decisions. Focusing primarily on the law in England and Wales, but with reference to multi-jurisdictional case-law and international instruments, it will consider whether the law provides compassionate approaches and outcomes in end-of-life decision-making, and the implications of compassion for legal certainty.
\end{abstract}

\section{Introduction}

Law and law-making have long been regarded as an objective process untouched by emotion (Littleton, 1987; Posner, 200I). There is an expectation that the law applies equally to all and offers impartial adjudication of disputes and cases without being influenced by bias, personal preference or other external factors. On this understanding, it is argued that legal reasoning should be rational, objective and dispassionate so that outcomes are consistent and certain (Maroney, 20II). In essence, what is referred to here is the doctrine of precedent, which dictates that like cases should be decided alike, and different cases differently. Yet slavishly following that doctrine would allow very limited scope for legal development or for judges to distinguish cases or exercise discretion: cases might even be able to be decided without the involvement of courts at all. However, that is not the way the common law operates, and instead cases are routinely distinguished on the facts or the law, and there is creativity in determining what distinguishes one case from another. Indeed, 'it is the creative function of judges that makes the job important' (Griffith, I997, p. 282) and this creativity extends beyond merely distinguishing one case from another - it is central to the process of legal reasoning. Furthermore, judges are informed by their own experiences and influences, and 'do not enter public office as ideological virgins' (Cameron, I990).

Neil MacCormick acknowledges that the claims to rationality and objectivity that characterise legal reasoning are not, and cannot be, the whole picture. He argues that '[I]t is of course possible that judges always or sometimes have subjective reasons motivating them to decide cases as they do which are quite other than the justifying reasons they give', and that 'our moral, like our legal, life has a necessary social setting, which provides us with the basis of rules and principles of action in new or difficult circumstances' (MacCormick, I978, p. I24). Taking the social setting into

* Professor of Healthcare Law and Bioethics, Southampton Law School, University of Southampton, UK. E-mail: H.Biggs@soton.ac.uk. 
account means that 'reason alone cannot wholly determine what we ought to do' (p. 265, emphasis in original) and that other factors, such as compassion, make for more realistic decision-making (Nussbaum, 1996). Nevertheless, to introduce such factors into legal reasoning and decisionmaking risks not only compromising legal certainty, but also raises concerns about arbitrary outcomes and the possibility that injustice might be done.

There are, however, some areas where it is necessary for legal decision-making to take account of the individuality of each case and to reach outcomes that might be similarly individualistic because they apply to the very specific aspects of each case. Health-care law is one such area, where cases that appear alike may legitimately be treated very differently due to concerns for the welfare and best interests of those involved (Veitch, 2007). It is acknowledged in the common-law cases, and specifically in statutes like the Mental Capacity Act 2005 in England and Wales, that each case is individual and dependent upon its own facts and the persons involved. The highly subjective nature of the facts of many health-care law cases, and the need for outcomes that reflect that subjectivity and demand a compassionate and caring response, presents challenges to the conception of the law as a dispassionate arbiter of disputes or protector of rights. Health-care cases concern issues relating to the most vulnerable in society, including those with physical or mental impairment, those who cannot make decisions on their own behalf and others who wish to make decisions that are at odds with medical opinion or the law, such as refusal of life-sustaining treatment or caesarean section or requests for assisted dying. End-of-life cases in particular often involve disputes around suffering, and the best way to respond to physical or emotional suffering. These cases therefore demand a highly individualist and compassionate approach that acknowledges and reacts to the needs and desires of those involved and responds compassionately because, as Susan Bandes explains, 'compassion's importance lies in its ability to aid decision-makers in understanding what is at stake for the litigant' (2017, this issue, p. 184). Such cases also raise globally applicable questions about discrimination, or equal protection, as well as concerns for safety, the assessment of best interests, the exercise of individual autonomy and the alleviation of suffering.

Feldman and Kuyken have usefully defined compassion in relation to human suffering as 'the capacity to meet pain with kindness, empathy, equanimity and patience' (Feldman and Kuyken, 20II, p. I53). For them, compassion 'should have healing suffering as it its goal' (Feldman and Kuyken, 20II, p. I52) and 'is an orientation of mind that recognizes pain and the universality of pain in human experience' (p. I44). With regard to assisted dying, it has been suggested that compassion can be exercised by adopting a case-by-case approach that is tailored to the individual and accords with the patient's own judgment of his or her suffering. This is thought to be particularly important because such an approach complies with the person's own values and understanding of what it is to have a good death (Brody, I992). In this way, compassion in end-oflife decision-making is clearly related both to empathy for the suffering of the patient while avoiding moral condescension (de Zulueta, 2015) and also to respect for the dignity of the person, particularly in relation to his or her autonomy and self-determination. These understandings of compassion will be used to inform the following discussion.

With a specific focus on the law of England and Wales, but with reference to other jurisdictions and international instruments such as the UN Convention on the Rights of Persons with Disabilities 2012 and the Charter of Fundamental Rights of the European Union, this paper will evaluate the extent to which law's traditionally claimed objectivity, or dispassion, is, or is not, undermined by the introduction of concerns about compassion into judicial and executive decisions in the context of health-care law. It will consider the role that compassion should play in the cases discussed, especially in relation to cases concerning end-of-life decision-making for people who lack mental capacity, and with regard to assisted dying for those who are physically incapacitated. In this context, compassion is taken as a mechanism to help alleviate suffering, and more 
specifically as recognition that suffering is an individualistic phenomenon that may be physical or emotional. These topics provide a lens through which the role of compassion might be viewed, and can be used as a focus to illustrate resonances in areas beyond this application.

\section{End-of-life decisions, capacity and best interests}

Perhaps the clearest example of a situation where compassion might be expected to play a part in judicial deliberation concerns decision-making for those who lack the capacity to decide for themselves at the end of life. Not only are such people amongst the most vulnerable in society and deserving of compassion and the highest degree of protection, but the avoidance of suffering is often central to decisions about providing or withdrawing treatment at the end of life. There are numerous mechanisms to deal with such matters in relation to children, but the focus here is on a range of varied circumstances where decisions must be made for incapacitated adults who are unable to give or refuse consent to medical interventions. Ordinarily, a valid consent is required to legitimate the kinds of physical contact involved in medical treatment. Where that contact extends beyond the scope of activity that can be legitimated by lawful consent, such as surgery, which would otherwise be regarded as actual or grievous bodily harm, its authority derives from the fact that proper medical treatment requiring such intervention is a category that stands outside of the criminal law (Airedale NHS v. Bland [I993] AC 789, per Lord Mustill; $R v$. Brown [I994] I AC 2I2, per Lord Mustill). Consent would still be required, however, to authorise the performance of that treatment, and is generally regarded as the mechanism through which patients can exercise their autonomy.

Unlike other jurisdictions, there was historically no provision for proxy decision-making for adult patients in England and Wales. Here, the treatment of mental ill-health was provided for in specific legislation through the years (Mental Health Act I959, Mental Health Act I983) but health and welfare decisions for those who lacked or had lost mental capacity due to illness or trauma would be made by the High Court in the exercise of its inherent jurisdiction. The High Court retains this inherent jurisdiction today to make decisions where a person is judged to be vulnerable but nevertheless retains decision-making capacity but, in 2007, the Court of Protection was established by the Mental Capacity Act 2005 (MCA) to take decisions about health and welfare on behalf of incapacitated adults who cannot decide for themselves. The court must establish that the person lacks capacity prior to exercising its power, and thereafter decisions must be taken according to their best interests. Further discussion of the application of the best-interests test will follow below, but it is important to first determine when the test will be applied, or how a lack of capacity is assessed.

\subsection{How is capacity established?}

Some adult patients may have never developed significant decision-making capacity due to a learning disability or other impairment, and so may never have been able to exercise their autonomy. For others, however, incapacity is the result of trauma or illness, or is transient, as is the case in some forms of dementia or mental illness, or because the patient is temporarily rendered unconscious. Decision-making capacity attaches to the particular decision being made, rather than to the person concerned, and the law in England and Wales presumes that all adults have decision-making capacity unless it is established that they do not (MCA 2005, section I). Competence can fluctuate so that a person may have capacity to participate in day-to-day decisions around everyday choices and experiences, but not to make more serious or complex decisions about their health or finances. The law therefore requires an individualised assessment of capacity that maximises the person's autonomy and is, on the face of it, consistent with the Council of Europe Recommendations Concerning the Legal Protection of Incapable Adults 
(Recommendation No R (99)4 of the Committee of Ministers to Member States on Principles Concerning the Legal Protection of Incapable Adults (Adopted $23^{\text {rd }}$ February 2003), Principle 3 ) and also the United Nations Convention on the Rights of People with Disabilities (General Assembly Resolution 6I/I06 (2006), Article I2), both of which promote the maximisation of autonomy, where possible, and respect for the values of the patient.

Under the MCA, section 3(I), a person is determined to lack capacity if he or she cannot understand and retain information relevant to the particular decision, use that information and weigh it up as part of the decision-making process, and communicate their decision. This form of assessment appears dispassionate and clinical, but the Code of Practice produced under section 42 of the MCA (Mental Capacity Act 2005: Code of Practice, TSO, 2007) provides guidance on the practicalities associated with assessing capacity, and allows for a more individualised approach due largely to the types of personnel it expects to be involved in assessing capacity. Aside from clinicians, it cites multidisciplinary teams, including psychiatrists and speech and language specialists, as the kinds of personnel who ought to contribute to the assessment. The participation of a range of health-care professionals involved in the day-to-day care of patients allows for the detailed patient-centred assessment of each case based on an understanding of the needs and preferences of the person concerned, which might be expected to be based in compassion. Nevertheless, it has been suggested that the judicial approach, both before and after the enactment of the MCA, has 'almost invariably accorded with that of the medical expert(s)' and 'some judges appear to prefer the evidence of independent experts who do not have an immediate relationship with the person whose capacity is at issue' (Donnelly, 2009, p. 470). It is uncertain why this preference arises, but it suggests a leaning towards a dispassionate assessment based on objective criteria, rather than a compassionate approach that properly reflects the individuality of the patient and responds to their suffering based on empathy and the human experience.

Regardless of these potential shortcomings in the assessment process, once it is established that the patient lacks decision-making capacity, important medical decisions will be taken for them according to their best interests. Donnelly is concerned about the possible influence of the assessor's values on the determination of whether or not a person lacks decision-making capacity in terms of how these values are also mirrored in the assessment of best interests. The implications of this concern will be discussed below.

\subsection{Best-interests assessment}

Judicial understanding of best interests and its application was developed in a series of cases towards the end of the twentieth century (Re A (Male Sterilisation) [2000] I FLR 549; Re F (Mental patient sterilisation) [1990] 2 AC I; Re SL (Adult Patient) (Medical Treatment) [200I] Fam I5). The factors to be considered in determining the best interests are now enshrined in the MCA 2005, and the accompanying Code of Practice introduced guidance stating that 'all relevant factors that it would be reasonable to consider' should be taken into account in determining the best interests of a patient (MCA Code of Practice (2007), para. 5.7). The relevant factors include 'a wide range of ethical, social, moral, emotional and welfare considerations' (Re MM (an adult) [2007] EWHC (Fam), para. 99, per Munby J.), including the patient's wishes, feelings, beliefs and values under section 4(6), MCA. Where these are in tension with one another, a balance-sheet approach should be adopted (Re A (Male Sterilisation) [2000] I FLR 549, 560, per Thorpe L.J.) that lends weight to the different factors according to their perceived importance. The assessment of best interests in the court must therefore involve a real understanding of the patient and what is at stake for them. Where possible, and to maximise autonomy, this must take account of what her or his view would be about the situation in which the decision has to be taken. Factors to be considered include beliefs, life experiences, values and any wishes expressed or alluded to, and it seems clear that this is has the potential to elicit a compassionate response. To take time to understand a 
person in this level of detail demands empathy, and must intuitively provoke a subject-orientated approach that pays heed not just to their perceived suffering, but also to their attitude to suffering. Best-interests assessment might therefore be expected to include a consideration of what would be a compassionate approach to the person concerned and the outcomes of any decision to be made (Eldergill, 20I5) as well perhaps as some appreciation of the wider context of care and community obligation (Bandes, I990).

However, although the best-interests test has been central to decision-making for those who lack the capacity to decide for themselves, it has often been criticised. The Australian High Court is amongst these long-standing critics, arguing that

'the best interests approach offers no hierarchy of values which might guide the exercise of discretionary power ... in the absence of legal rules or a hierarchy of values, the best interests approach depends on the value system of the decision-maker.' (Department of Health and Community Services v. JWB and SMB (Marion's Case) [1992] HCA I5, para. I4, per Brennan J.)

Similarly, Ian Kennedy describes best interests as 'a somewhat crude conclusion of social policy' that allows the court to 'respond intuitively to each case while seeking to legitimate its conclusion by asserting that it is derived from the general principle contained in the best interests formula' (I99I, pp. 90-9I).

Two issues in particular arise from these criticisms, both of which chime with the concerns for certainty and dispassionate, objective decision-making in the law expressed at the beginning of this paper. Kennedy is concerned about the lack of transparency in decision-making and the fact that judges nod towards an apparently established principle that is at best opaque and at worst invisible. The judgment in Marion's Case is more scathing and raises a deeper concern: it suggests that it is not merely that best interests as a principle is hard to pin down, but that the entire decision-making process may be subverted by reflecting outcomes preferred by a decision-maker who has not only imported their own values, but has also neglected some, if not all, of the actual interests of the person affected by the decision. Such an outcome would not seem to empathise with the sufferer and would therefore be neither compassionate nor just.

Although there has been a significant lapse of time since Kennedy's critique and Marion's Case, more recent case-law indicates that outcomes can still be influenced by the biases of the decisionmaker to the detriment of the stated interests of the patient who sought to avoid suffering and indignity. In $W v$. $M$ and Ors [20II] EWHC 2443, $M$ had been in a minimally conscious state for several years after suddenly suffering viral encephalitis resulting in extensive and irreparable brain damage. She clearly lacked the capacity to make her own health-care decisions and had initially been diagnosed as being in a vegetative state, prompting her family to apply for a court order authorising withdrawal of artificial nutrition and hydration (ANH). Further diagnostic investigations revealed a low level of consciousness and awareness, and the diagnosis was subsequently revised to minimally conscious state. In the meantime, jurisdiction had transferred to the Court of Protection under the MCA 2005 and it fell to this court to determine whether it would be lawful to withdraw ANH. Although there was extensive precedent for withdrawal of ANH from patients in permanently vegetative states in various jurisdictions (e.g. Bland; Law Hospital NHS Trust v. Lord Advocate 1996 SLT 848; Gardner; re BWV [2003] VSC 173), no court in England and Wales had previously been asked to authorise withdrawal of ANH from a patient in a minimally conscious state.

There was no formal record of what $M$ 's wishes would be in this situation, but she had witnessed the experiences of her grandmother and her father, both of whom were institutionally cared for in the final stages of their lives. On this basis, her family members were convinced that $M$ would not have wished to be kept alive in the minimally conscious state she had fallen into. They described $M$ as 
'fiercely independent' (para. I07) and testified that $M$ herself had expressed the view that 'she would rather shorten her life by ten years rather than have someone look after her' (para. I07). Her devoted life partner was adamant that 'she wouldn't want to continue with this burdensome life with a lack of dignity' (para. I I g).

Empathising with this position, and respecting $M$ 's self-determination, would seem to indicate that a compassionate outcome would support the application for withdrawal of ANH. Respect for personal autonomy is widely regarded as the primary principle in health-care law, based on philosophical understandings that the law should give effect to the patient's own preferences and attitude to suffering, since they reflect her will (Dworkin, I988). The family were certain that $M$ 's values would mean that she would oppose continued treatment in this situation, even though she had no formal advance directive. In Bland ([1993] All ER 82I, 866), Lord Goff supported the view, endorsed by Lord Mustill, that the right to self-determination remains and should be respected even after capacity is lost. But, after hearing the evidence, Baker P., the judge in $W v$. $M$ and Ors, promulgated a strong presumption in favour of the sanctity of life. He paid heed to the opinions of the family, and their view of what the patient would consider to be in her best interests, stating that 'whilst I take these statements into account, they are not binding and in all the circumstances I do not consider they carry substantial weight in my decision' (para. 6). He went on to prioritise factors he favoured himself in his determination of what was in her best interests: '.. the factor which does carry substantial weight, in my judgment, is the preservation of life' (para. 7), and concluded: 'In my judgment, the importance of preserving life is the decisive factor in this case' (para. 249), which demonstrates the scope identified in the judgment in Marion's Case for the value systems of decision-makers to influence the assessment of best interests.

The patient in $W v$. M and Ors was a fit, active and healthy forty-two-year-old woman who was preparing to leave for a ski holiday when the tragic events occurred that left her in a minimally conscious state. It is not surprising therefore that she had not made a formal advance declaration of what her wishes would be if she were to become minimally conscious: that was an entirely unforeseen situation. A compassionate approach to best interests should have taken greater account of this context and prioritised the lifestyle and life expectations of $M$ and her family. The MCA, section 4(6) clearly expects that decisions will accord with the values of the patient, where these are known, and the family articulated $M$ 's views as strongly as they were able, but were overruled. Consequently, while best interests has the potential to locate compassion at the heart of the decision-making process, without a clearly defined hierarchy of factors to be considered, it may fail to do so. M's loved ones strongly demonstrated compassion by advocating for her point of view as they saw it, with her partner stating: 'It's not about us. We're irrelevant. I could only speak up for her, knowing her views and opinions. We're her voice' (para. I2I). It would seem, from the testimony of M's family, that their understanding of what she would have wanted for herself was based on her own compassionate response to the indignity she perceived for her relatives when they were rendered fully dependent upon others. To prioritise sanctity of life over her own compassion-based values in the judgment demonstrates a neglect of $M$ 's suffering that ignores the central relevance of her loss of personhood by failing to respect her wishes (Cassell, I982). If the decision is to be taken according to her best interests, then what she regarded herself as compassionate ought properly to be regarded as a key interest to be respected, if not her best interest.

There are of course sound arguments as to why a judge might seek not to uphold the apparent wishes of a patient like $M$ who has not formally expressed an opinion about what their wishes would be. The first is that the fact that the incapacitated patient did not formalise her wish might indicate that she was not fully committed to it, although, in $M$ 's case, there was adequate evidence of the values she held in her life to lend support to the family's portrayal of her wishes. In addition, some commentators have raised concerns about the personhood or identity of the 
individual who has lost capacity and whether previously expressed opinions and wishes can be regarded as reliable (Ryan, I996; Dworkin, 1993). At issue is whether a person who makes an advance declaration about how they wish to be treated in particular circumstances but has not experienced those circumstances can truly anticipate that eventuality and make a safe decision about it. Ryan makes a cogent argument that the person who becomes incapacitated may express a contemporaneous view and be content with the situation within which they find themselves at the time because their outlook on life, if indeed they continue to have one, has changed. He uses this to cast doubt on the probity of the advance decision and raise concerns about the reliability of wishes expressed about abstract events that have not been experienced. Dworkin, however, considers the issue as demonstrating a tension between the contemporary autonomy of the individual and their precedent autonomy, and draws an alternative conclusion. He argues that any decision on the interests of such a patient ought to have regard for the integrity of her autonomy in the round. The person who has lost capacity to decide lacks the autonomy of her former self, leading to the conclusion that her previously held wishes and values should be decisive (Dworkin, I993, pp. 218-237). A compassionate response is designed to relieve suffering, and it can be inferred that the values and wishes of a person, like $M$, indicate that her preference would be to avoid suffering by having ANH withdrawn. Failing to respect this is acting against the wishes and values of the person concerned and risks compounding their suffering, first by physically failing to relieve it and second by insulting their autonomy and dignity (de Zulueta, 2015).

Affording this level of significance to autonomy as a means of exercising compassion where the patient is incapacitated requires that the judge or decision-maker regards those wishes and values in the same way as they would if the person had capacity. Coggon suggests that some judges decline to do so for fear that it would effectively mean 'replacing the best interests standard with a substituted judgment test', which requires the decision-maker to act as a proxy for the incapacitated person (Coggon, 2016). Such an approach is prevalent in other jurisdictions, but has not been favoured in England and Wales, as the case of $W$ v. $M$ and Ors discussed above indicates. However, more recent jurisprudence suggests that the application of the MCA and best-interests assessment may be shifting towards a more compassionate, patient-centred emphasis. For instance, in $M v$. Mrs $N$ and Others [2015] EWCOP 76, a later case concerning a minimally conscious patient, Hayden J. held at para. 75 that 'it would be disrespectful to Mrs. $\mathrm{N}$ to preserve her further in a manner that I think she would regard as grotesque' (emphasis in the original). Accordingly, ANH was discontinued in line with the patient's wishes and values. This outcome is compassionate because it respects the patient's autonomy and values, and mirrors the patient's own understanding of what compassion would look like in this situation.

The foregoing discussion seems to indicate that the best-interests test has not always been the best way to generate compassionate decision-making for those who cannot decide for themselves. The courts have grappled with the extent to which best interests can be precisely defined and the factors that must be taken into account in its determination. In a first-instance case involving a seriously ill neonate, Hedley J. suggested that 'the infinite variety of the human condition never ceases to surprise and it is this fact that defeats any attempt to be more precise in a definition of best interests' (Portsmouth NHS Trust v. Wyatt [2004] EWHC 2247, per Hedley J.). Shortly afterwards, however, a strong argument was advanced in favour of reflecting the patient's autonomy and expressed views in decisions about whether to withhold or withdraw treatment from an incompetent patient:

'(I) the assessment of best interests has to be made from the point of view or perspective of the particular patient and (2) the touchstone of best interests in this context is intolerability.' (R (Burke) v. GMC (Official Solicitor intervening) [2004] EWHC I879, para I I I, per Munby J.) 
That was swiftly followed by the decision in Burke in the Court of Appeal, where it was stated that '[w] e do not think it is possible to attempt to define what is in the best interests of a patient by a single test' (GMC v. Burke [2005] EWCA I003, para. 63, per Lord Phillips M.R.), leaving the way open for judicial discretion to continue.

It is clear then that, until relatively recently, the courts in England and Wales seemed to be wedded to a dispassionate approach to determining the best interests of patients who lack capacity to decide for themselves, regardless of the known values or previously expressed views of the patient. But it is now acknowledged that a genuine assessment of best interests must identify the individuality of the patient and what her or she would regard as his or her best interests, and that to do this the court must 'consider matters from the patient's point of view' (Aintree University Hospital NHS Foundation Trust v. James [2013] UKSC 67, per Lady Hale). By properly understanding, and recognising the wishes and values of the patient rather than conducting a dispassionate objective analysis, the court can act compassionately and respond in a 'holistic way' to the needs of the person concerned.

This discussion has identified concerns around compassionate end-of-life decision-making for people who lack the capacity to decide for themselves and the beginnings of a shift from dispassionate decision-making to a compassionate person-centred approach. The next section will outline different concerns in relation to those who have decision-making capacity and seek assisted dying.

\section{Assisted dying and compassion}

Many years ago, Ronald Dworkin wrote that '[e]very day, rational people all over the world plead to be allowed to die. Sometimes they plead for others to kill them ... because they are unwilling to live in the only way open to them' (Dworkin, I993, p. I79). Later, the European Court of Human Rights stated that

'[i]n an era of growing medical sophistication combined with longer life expectancies, many people are concerned that they should not be forced to linger on in old age or in states of physical or mental decrepitude which conflict with strongly held ideas of self and personal identity.' (Pretty v. United Kingdom (2002) 35 EHRR I, para. 65)

Both statements speak to the potential for great human suffering when a person is unable to exercise autonomy and control at the end of life and seeks assisted dying to relieve that suffering - a situation that needs to be met with compassion.

Some jurisdictions, notably the Netherlands, Switzerland, Belgium and some states in the US (California, Oregon, Vermont and Washington), amongst others, have responded compassionately and enacted permissive legal reforms to enable such persons to be assisted to die. However, in England and Wales, assisted suicide remains prohibited by the Suicide Act I96I, as amended by the Coroners and Justice Act 2009, section 59, and euthanasia is regarded as homicide under common law. The Suicide Act 196I was introduced largely to abrogate 'the rule of law whereby it is a crime to commit suicide' (Suicide Act I96I, section I). Prior to that, suicide was regarded as self-murder and a person who attempted suicide could be prosecuted but, by the I960s, it had become accepted that such people needed compassion and support, rather than punishment. Parliament was clear, however, that, for the protection of the vulnerable, assisting suicide should remain a crime of the highest order, attracting severe punishment (Calvert-Smith and O'Doherty, 2003). Nonetheless, assisted dying has been the subject of numerous challenges in England and Wales, Scotland and in other commonwealth or former commonwealth countries, such as Australia and New Zealand, where assisted dying is also currently outlawed. This section will 
discuss some of the more prominent of these legal challenges in England and Wales, and some recent developments in Canada and New Zealand, to identify the role that compassion plays in this context.

\subsection{Assisted suicide}

Assisted suicide involves a person performing the final act that results in his or her death with assistance from another person. Under the Suicide Act, assisting suicide is defined as any act capable of encouraging or assisting another person to commit suicide or attempt to commit suicide with the intention that the act(s) will encourage or assist the suicide. Many of the cases brought before the courts concern people suffering from debilitating physical conditions, such as motor neurone disease, which prevent them from committing suicide. Diane Pretty was one of these people, and brought her case before the domestic courts early this century ( $R$ (on the application of Pretty) v. DPP [200I] EWHC Admin 788), and ultimately appealed to the European Court of Human Rights (ECtHR) (Pretty, 2002). Amongst other claims, she argued that the prohibition on assisted suicide was contrary to her right to self-determination, as articulated through Article 8 of the European Convention on Human Rights. However, although the ECtHR was sympathetic to her position, her claim was rejected, primarily because to allow it might place others, more vulnerable than her, at risk, which is explicitly provided for in Article 8(2), which speaks to 'the protection of health or morals, or the protection of the rights and freedoms of others' (Article 8(2)).

Diane Pretty was not a vulnerable person, despite her illness. She was fiercely independent, to the extent that she applied for her first passport so that she could travel to the court to hear the verdict even though she was wheelchair-bound. She sought to avoid suffering a painful and distressing death by being assisted to die before her disease progressed to that point, and was steadfast in that desire. She wanted to die in the same way as she had lived: independently and in control as an autonomous being. Out of compassion, her husband had reluctantly agreed to assist her in suicide, provided that he would not be prosecuted. Neither of them wanted to break the law, as Mrs Pretty made clear: 'I want my family to remember me as someone who respected the law, and asked in turn that the law respected my rights' (Dyer, 2002b). Instead, the courts conducted a dispassionate application of the law and Diane Pretty suffered the kind of death she sought to avoid: one that lacked dignity and was contrary to her autonomous wishes and the values by which she had lived her life. Her husband's compassionate words are reminiscent of those quoted above from $M$ 's partner: 'Diane had to go through the one thing she had foreseen and was afraid of - and there was nothing I could do to help' (Dyer, 2002a). A more compassionate outcome would have surely avoided this suffering and respected the autonomy and values of Mrs Pretty.

A later case, $R$ (Purdy) $v$. DPP [2009] UKHL 45, was brought to clarify the circumstances under which a prosecution might be brought under the Suicide Act I96I if a person was assisted to travel to Switzerland for an assisted suicide. Debbie Purdy suffered from multiple sclerosis and envisaged that, at some point in the future, she might wish to end her life in Switzerland, where, unusually, foreign nationals are permitted to access assisted dying. She would not, however, be able to travel without assistance and was concerned that those who helped her might face criminal charges as a result. Although assisting suicide is a crime, prosecution is not automatic and, under section 2(4) of the Suicide Act 1961, the Director of Public Prosecutions has discretion over when to implement proceedings. Purdy argued that the factors to be considered in exercising that discretion were unclear, and the House of Lords, as it then was, agreed and required that guidance be issued outlining the factors to be considered in deciding whether to bring a prosecution. Key amongst these factors is the sixth of sixteen that tend in favour of prosecution, which explains that prosecution is more likely if the person assisting is 'not wholly motivated by compassion' (CPS, 20Io, para. 43(6)), while prosecution is less likely if 'the suspect was wholly motivated by compassion' (CPS, 2010, para. 45(2)). In this way compassion is enshrined in the 
guidelines, albeit without a clear definition and in contradiction of usual standards for criminal prosecution, which pays no heed to motive (Biggs, 20II). The emphasis on compassion is, understandably, very narrow, pertaining purely to the circumstances of decisions whether or not to prosecute. In the broader context, however, concerns might legitimately be raised about the lack of compassion in a law that prohibits autonomous persons from being assisted to die at home and yet regularly fails to prosecute those who assist them to travel overseas to access assisted dying. Indeed, prior to a referendum in the canton of Zurich on whether to curtail access to assisted suicide for foreign nationals, some of those eligible to vote expressed the view that, if the person's home state was not sufficiently compassionate to allow the service, then it was only ethical for Switzerland to continue to do so: 'it is a mark of civilised society to help people to die if they are suffering' (Walsh, 20II). The electorate voted overwhelmingly in favour of continuing to offer assisted suicide.

The Canadian the case of Rodriguez v. British Columbia (Attorney General) (1993) I07 DLR ( $4^{\text {th }}$ ) 342 concerned facts very similar to those in Pretty in a challenge by Sue Rodriguez to section 24I(b) of the Canadian Criminal Code, which she argued violated her constitutional rights to life, liberty and the security of the person by prohibiting assisted suicide. Offering reasoning similar to that later adopted in Pretty, the Supreme Court dismissed the application, deciding by a five-to-four majority in favour of the sanctity of life and protecting vulnerable persons from abuse, even though section 24I(b) did impact upon the security of her person under section 7 of the Canadian Charter of Rights and Freedoms. There was no explicit mention of compassion in the judgment, but the dissenting judgments paid particular attention to the suffering that could be avoided if assisted dying were permissible:

'... it follows that the right to die with dignity should be as well protected as any other aspect of the right to life. State prohibitions that would force a dreadful, painful death on a rational but incapacitated terminally ill patient are an affront to human dignity.' (Rodriguez, I993, p. 4I3, per Cory J.)

Following Rodriguez, the law appeared to be settled but, in 2015, the case of Carter v. Canada (Attorney General) [20I5] SCC 5 became 'one of the most significant decisions ever issued by the Supreme Court of Canada' (Chan and Somerville, 2016, p. I44). In this ground-breaking judgment, the unanimous decision of all nine judges overturned Rodriguez, finding that the complete prohibition of physician-assisted death, which they took to include euthanasia and physician-assisted suicide, was a violation of section 7 of the Canadian Charter of Rights and Freedoms. Arguing compassionately from the outset that perpetuating avoidable suffering is inhumane, the court declared that:

'... people who are grievously and irremediably ill cannot seek a physician's assistance in dying and may be condemned to a life of severe and intolerable suffering. A person facing this prospect has two options: she can take her own life prematurely, often by violent or dangerous means, or she can suffer until she dies from natural causes. The choice is cruel.' (Carter, 2015, para. I)

The effect of this judgment was far-reaching. It rendered void the provisions in the Criminal Code that prohibited assisted dying, and the parliament of Canada subsequently amended section I4 of the Criminal Code to permit medical assistance in dying (BILL C-I4). In doing so, it provides an exemption from prosecution for culpable homicide for medical and nurse practitioners who 'provide a person with medical assistance in dying' (section 227(I)) provided they do so in accordance with section 24I.2 of the Criminal Code. Section 24I.2(I) sets out the criteria under which assistance in dying may be provided, including that they are an adult over eighteen years of 
age, are eligible to receive government-funded health services and are suffering from 'a grievous and irremediable medical condition'. They must also have made a voluntary and uncoerced request for medical assistance in dying and have consented to this after being fully informed of available alternatives. Clear definitions of 'grievous and irremediable medical condition' are given in section 24I.2(2), which also includes a provision that death 'has become reasonably foreseeable' and that the illness, disease or disability causes 'enduring physical or psychological suffering'. Safeguards under section 24I.2(3) include the need to ensure that the person's eligibility has been verified by an independent practitioner, that the request for assistance was made in writing in front of witnesses and that at least ten days elapse between the request being made and its implementation. The Bill received assent on I7 June 2016 and demonstrates a clear recognition of the need to relieve the suffering of terminally ill people who have the capacity to make an autonomous choice, rather than merely upholding the existing legal rationale. It is a truly compassionate response to a widespread social concern.

\section{Conclusions}

This paper has explored the relationship between the orthodoxy of precedent, rationality and certainty and the individualistic approach to health-care cases informed by compassion and the values and desires of those involved. Using health-care law cases as examples, it has shown that compassion can be brought to bear on legal reasoning and that, as Neil MacCormick explained, 'reason alone cannot wholly determine what we ought to do' (I978, p. 265, emphasis in original).

It is clear that the traditional idea of dispassionate law is not undermined by the person-centred approach adopted in these health-care law cases. Compassion and the alleviation of all forms of suffering are pivotal in this context because the facts and the outcomes are specific to the individual cases. Although often apparently similar, the nuances involved demand that like cases are not always treated alike and, while legal reasoning is expected to be dispassionate, these cases call for a form of discretion based on compassion that can properly reflect the best interests of the patients concerned. By respecting the values and wishes of the individual patient, the true best interests of the person will be reflected in the decision-making process and the outcomes, and compassion will be at centre stage.

Health-care law cases concerning end-of-life decision-making demand 'both the recognition of our common humanity and the honouring of the individual narrative' (de Zulueta, 2015, p. 89). The cases highlighted here have demonstrated that, in England and Wales, the application of the best-interests test in relation to making decisions for those who have lost mental capacity is beginning to evolve a more compassionate approach that foregrounds the values of the individual concerned. In this way, it is beginning to take cognisance of the emotional environment as well as the purely physical needs of the patient, to honour the life choices of the patient before she lost capacity and thereby pay heed to the avoidance of suffering for the patients and their families (Aintree, 2013; $M v$. Mrs $N$ and Others, 2015). There is more limited evidence of a shift towards a compassionate basis for permissive legal change in relation to assisted dying, and the decision in Carter v. Canada and subsequent legal reform have the potential to be informative, if not transformative, when future cases arise in England and Wales.

\section{References}

Bandes, S.A. (I990) 'The Negative Constitution: A Critique', University of Michigan Law Review 88: 227 I-2347.

BANDES, S.A. (2017) 'Compassion and the Rule of Law', International Journal of Law in Context I3(x): I84-I 96. 
BIGGS, H. (20I I) 'Legitimate Compassion or Compassionate Legitimation? Reflections on the Policy for Prosecutors in Respect of Cases of Encouraging or Assisting Suicide', Feminist Legal Studies I9(I): 83-9I.

BRODY, H. (I992) 'Assisted Death: A Compassionate Response to a Medical Failure', New England Journal of Medicine 327: I384-I388.

CAlvert-Smith, D. and o'Doherty, S. (2003) 'Legislative Technique and Human Rights: A Response', Criminal Law Review 384-390.

CAmeron, E. (I990) 'Judicial Accountability in South Africa', South African Journal on Human Rights 6(2): $25 \mathrm{I}-265$.

CASSELL, E.J. (I982) ‘The Nature of Suffering and the Goals of Medicine', New England Journal of Medicine 306(II): 639-645.

CHAN, B. and somerville, M. (20I6) 'Converting the "Right to Life" to the "Right to Physician-Assisted Suicide and Euthanasia": An Analysis of Carter v Canada (Attorney General), Supreme Court of Canada', Medical Law Review 24(2): I43-175.

CogGon, J. (20I6) 'Mental Capacity Law, Autonomy, and Best Interests: An Argument for Conceptual and Practical Clarity in the Court of Protection', Medical Law Review (forthcoming).

CPS (2010) Policy for Prosecutors in Respect of Cases of Encouraging or Assisting Suicide. London: UK Gov. Available at: $<$ www.cps.gov.uk/publications/prosecution/assisted_suicide_policy.html > (accessed 2 March 2017).

DE zulueta, P.C. (2015) 'Suffering, Compassion and "Doing Good Medical Ethics”, Journal of Medical Ethics 4I: 87-90.

Donnelly, M. (2009) 'Capacity Assessment under the Mental Capacity Act 2005', Legal Studies 29(3): 464-49I.

Dworkin, G. (I988) The Theory and Practice of Autonomy. Cambridge: Cambridge University Press. Dworkin, R. (I993) Life's Dominion. London: HarperCollins.

DYER, C. (2002a) “Free at Last”: Diane Pretty Dies', The Guardian, I3 May. Available at: <www. theguardian.com/society/2002/may/I3/health.healthandwellbeing $>$ (accessed 2 March 2017).

DYER, C. (2002b) 'Pretty's Legal Battle for Dignity in Death', The Guardian, I3 May. Available at: <www. theguardian.com/society/2002/may/I3/health.healthandwellbeingI (accessed 2 March 2017). eldergill, A. (2015) 'Compassion and the Law: A Judicial Perspective', Elder Law Journal 3: 268-278. feldman, C. and KUYken, W. (20II) 'Compassion in the Landscape of Suffering', Contemporary Buddhism I 2: I43-I 55 .

GRIFFITH, J.A.G. (I997) The Politics of the Judiciary, 5 th edn. London: Fontana.

KENNEDY, I. (I99I) 'Patients, Doctors and Human Rights' in R. Blackburn and J. Taylor (eds) Human Rights for the I990s. London: Mansell, 8I-I08.

LitTleton, C. (I987) 'In Search of a Feminist Jurisprudence', Harvard Women's Law Journal Io: I-7. MACCoRmick, N. (I978) Legal Reasoning and Legal Theory. Oxford: Oxford University Press.

maroney, T.A. (20I I) 'The Persistent Cultural Script of Judicial Dispassion', California Law Review 99: 629-68I.

nussbaum, M. (1996) 'Compassion: The Basic Social Emotion', Social Policy and Philosophy I3: 27-4I. POSNER, E. (200I) 'Law and the Emotions', Georgetown Law Journal 89: I977-20I 2.

RYAN, C. (I 996) 'Betting Your Life: An Argument against Certain Advance Directives', Journal of Medical Ethics 22(2): 95-99.

veItch, K. (2007) The Jurisdiction of Medical Law. Aldershot: Ashgate.

wALSH, F. (20I I) 'Swiss Vote to Continue Assisted Suicide', BBC News. Available at: http://www.bbc.co. uk/news/health-I34I0228 (accessed 2 March 2017). 